22. Schichi H. Cataract formation and prevention / H. Schichi // Expert Opion Invest Drugs. - 2004. - Vol. 13 (6). P. 691-701.

23. Spector A. Oxidative stress-induced cataract: mechanism of action / A. Spector // FASEB J. - 1995. - V. 9. P. 1173-1182.

24. Taylor A. Nutritional influences on risk for cataract / A. Taylor // Int. Ophthalmol. Clin. - 2000. - Vol. 40 (4). P. 17-49.
25. Truscott R. J. Age-related nuclear cataract-oxidation is the key / R. J. Truscott // Exp Eye Res. - 2005. - Vol. 80 (5). - P. 709-725.

26. Yablonski M. E. The presence of cataract as a predictor of mortality / M. E. Yablonski // Arch Ophthalmol. 2001. - Vol. 119 (10). - P. 1562-1563.

Поступила 31.01.2011

Рецензент д-р мед. наук А. А. Путиенко

\title{
EMOXIPIN INFLUENCE ON DEVELOPMENT OF EXPERIMENTAL CATARACT IN ANIMALS WITH KERATITIS
}

Usov V. Ya., Tarik Abou Tarboush, Kondratieva E. I.

\section{Odessa, Ukraine}

There were studied possibilities of increasing the stability of the eye lens by the antioxidant emoxipin in modeling light cataract in animals with keratitis. Under the condition of light cataract in experimental keratitis the pathological changes in the lens of the animals developed quicker and were more expressed in the last period of follow-up (30-40 weeks). The degree of pathological changes in the lens on the 30th and 40th week of the experiment were reliably lower under the influence of emoxipin ( $\mathrm{p}=0.033$ and $\mathrm{p}=0.018$ correspondingly). Emoxipin exerts a stabilizing effect on the lens eye both under the light influence and in modeling of keratitis in the conditions of natural light.

УДК 617.713-002.828-085:612.085.1

\section{ФОТОДИНАМИЧЕСКАЯ ТЕРАПИЯ С ИСПОЛЬЗОВАНИЕМ МЕТИЛЕНОВОГО СИНЕГО В КАЧЕСТВЕ ФОТОСЕНСИБИЛИЗАТОРА ПРИ ЛЕЧЕНИИ ГРИБКОВОГО КЕРАТИТА}

\author{
А. В. Зборовская, к. мед. н. \\ ГУ «Институт глазных болезней и тканевой терапии им. В. П. Филатова НАМН Украины»
}

Експеримент виконано на 30 очах кроликів породи шиншила. Модель грибкового кератиту була модифікована введенням в процес ін'єкцій циклофосфану, інстиляцій дексаметазону та сполученням внутрішньо- стромального введення добової культури патогеного тест-штамму Candida albicans (АТCC 885-653) з поверхневою скаріфікацєю з наступним інфікуванням тією же культурою. Лікування розпочиналось на третю добу (розвиток кератиту) і складалось з: в контрольній групі (15 очей) стандартна протизапальна терапія, в основній групі (15 очей) - до стандартної терапії долучали фотодинамічну антимікробну хіміотерапію з метиленовим синім (активуючий діодний лазер 630 нм, тривалість опромінення 3 хв). В результаті встановлено, що модифікована модель грибкового кератиту дозволяє отримати кератит середнього та важкого ступеня; застосування ФДТ з метиленовим синім дозволяє скоротити термін лікування та досягти загоєння рогівки з більш високим оптичним результатом.

Ключевые слова: грибковый кератит, фотодинамическая терапия, метиленовый синий

Ключові слова: грибковий кератит, фотодинамічна терапія, метиленовий синій

Введение. Грибковый кератит является одной из самых актуальных проблем среди инфекционных заболеваний глаз [3]. Наиболее высокие факторы риска развития грибкового кератита это травма роговицы, использование контактных линз, особенно для длительного ношения, и терапевтических бандажных контактных линз. Проведенные исследования показали, что частота грибковых кератитов вследствие травмы составляет 33-100\% случаев $[4,6,7]$. Факторами риска также являются сахарный диабет; постоянное и неадекватное применение кортикостероидов, местных глазных форм анестетиков при самолечении глазных травм [2]. Первый признак грибковой инфекции - центральный, парацентральный, или периферический инфильтрат роговицы с выраженным проявлением конъюнктивальной инъекции. Локализующиеся в центральной зоне роговицы патологические процессы обычно протекают более тяжело и с более серьёзным прогнозом, чем очаги возле лимба, и, в

(C) А. В. Зборовская, 2011 
большинстве случаев, они сопровождаются изъязвлением роговицы [3]. Естественное течение заболевания без лечения приводит к развитию гипопиона, помутнений и неоваскуляризации роговицы, десцеметоцеле с последующей перфорацией роговицы. Развитие серьезных осложнений - полного помутнения роговицы, стафиломы и эндофтальмита может в конечном счете привести к развитию слепоты.

Грибковые кератиты остаются важной проблемой в офтальмологии, что обусловлено отсутствием эффективных противогрибковых средств для местного применения. Разработано много экспериментальных моделей грибковых поражений глаз для изучения эффективности новых противогрибковых препаратов, однако каждые из них обладают рядом недостатков, что не позволяет воспроизвести эти модели [5].

Целью исследования было изучить в эксперименте на модифицированной модели грибкового кератита эффективность фотодинамической терапии с метиленовым синим.

МАТЕРИАЛ И МЕТОДЫ. Экспериментальное исследование проведено на 30 глазах 15 кроликов породы шиншилла массой 2,5-3 кг, самцах. За основу была взята модель грибкового кератита, предложенная W. BehrensBaumann в 2003 году [1]. Эта модель была нами модифицирована: за трое суток до выполнения вмешательства всем кроликам был назначен внутримышечно циклофосфан 1 раз в сутки, глазные капли $0,1 \%$ дексаметазона 4 раза в день в оба глаза. На четвертые сутки кроликам под местной анестезией оксибупрокаином на обоих глазах с помощью инсулинового шприца в строму роговицы в центральной области было введено 3 млн МТ в 0,1мл суточной культуры патогенного тест-штамма Candida albicans (ATCC 885-653). Затем выполнялась скарификация центральной зоны роговицы. Раневую поверхность роговицы инфицировали той же культурой Candida albicans. На третьи сутки к моменту начала лечения у кроликов развивался грибковый кератит. Глаза кроликов были разделены на две группы. На 15 правых глазах - контрольная группа, проводилась стандартная противовоспалительная терапия, мидриаз. На левых глазах (основная группа) на фоне стандартной противовоспалительной терапии и мидриаза, проводилась фотодинамическая терапия (ФДТ). Методика ФДТ заключалась в следующем: через 10 минут после трехкратной инстилляции 0,1 \% водного раствора метиленового синего (МС) проводилось облучение диодным лазером с длиной волны 630 нм на протяжении 3 мин. Течение процесса контролировали при помощи биомикроскопии, прижизненного окрашивания 0,1 \% флюоресцеином, оценки степени воспалительной реакции по балльной системе критериев [8]. Посевы с роговицы и конъюнктивальной полости проводились до инфицирования, на 3-и сутки после инфицирования и каждые 7 дней в ходе лечения. В процессе наблюдения выполнялось цветное фотографирование переднего отрезка глаза.

РЕЗУЛЬТАТЫ. После проведенного лечения и наблюдения получены следующие результаты. В контрольной группе с кератитом средней степени (8 глаз) через сутки после вмешательства у всех кроликов появились блефароспазм, гиперемия конъюнктивы, отделяемое из конъюнктивальной полости, эрозия роговицы, выраженный отек эпителия и наружных слоев стромы роговицы и стромальные инфильтраты роговицы (рис. 1). На третьи сутки по данным бактериологического исследования отмечался бурный рост Candida albicans, воспалительный процесс был выражен максимально. Затем наблюдался регресс воспалительного процесса. На восьмые сутки отмечалось уменьшение интенсивности отека эпителия роговицы, полная эпителизация нанесенной эрозии, что подтверждалось флюресцеиновой пробой. На 15-е сутки отмечалось постепенное рассасывание инфильтратов (табл.1). Длительность кератита средней степени (8 глаз) составила $(14,25 \pm 1,0)$ дней, исход - локальное стромальное помутнение с неоваскуляризацией (рис. 2). Роста патогенной флоры нет.

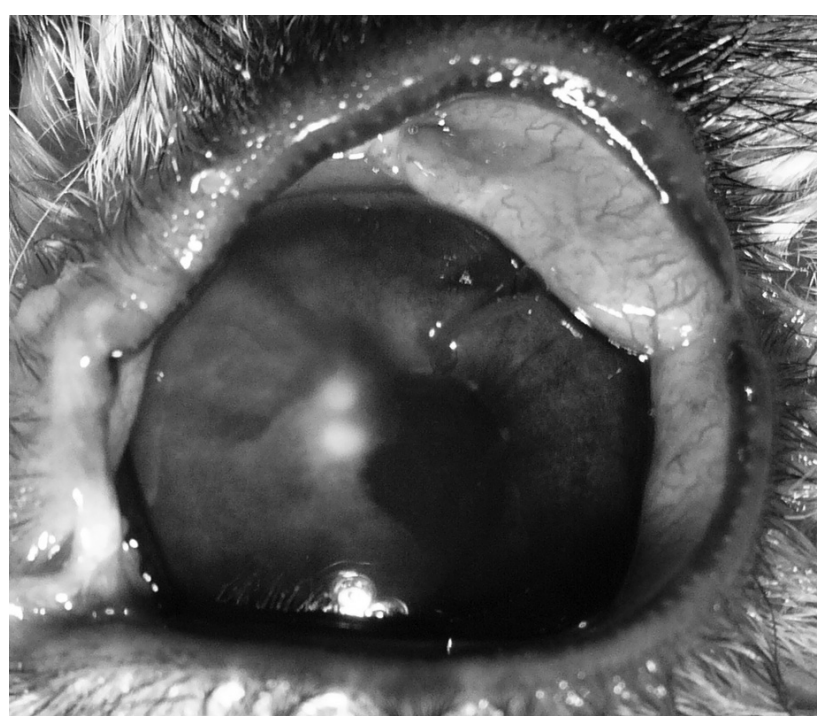

Рис. 1. Фотография глаза кролика контрольной группы с кератитом средней степени через сутки после вмешательства.

Таблица 1

Оценка (в баллах) течения моделированного грибкового кератита средней степени тяжести у кроликов контрольной группы (в баллах)

\begin{tabular}{|c|c|c|c|c|c|}
\hline Сутки & $\begin{array}{c}\text { Гипере- } \\
\text { мия конъ- } \\
\text { юнктивы }\end{array}$ & $\begin{array}{c}\text { Эрозия } \\
\text { рогови- } \\
\text { цы }\end{array}$ & $\begin{array}{c}\text { Отек ро-- } \\
\text { говицы }\end{array}$ & $\begin{array}{c}\text { Инфиль- } \\
\text { трация } \\
\text { роговицы }\end{array}$ & $\begin{array}{c}\text { Помут- } \\
\text { нение } \\
\text { рогови- } \\
\text { цы }\end{array}$ \\
\hline $\begin{array}{c}\text { До зара- } \\
\text { жения }\end{array}$ & $1,0 \pm 0,0$ & $1,0 \pm 0,0$ & $1,0 \pm 0,0$ & $1,0 \pm 0,0$ & $1,0 \pm 0.0$ \\
\hline 1 & $3,0 \pm 0,0$ & $2,0 \pm 0,0$ & $2,4 \pm 0,5$ & $2,4 \pm 0,5$ & $1,0 \pm 0,0$ \\
\hline 3 & $3,6 \pm 0,4$ & $1,9 \pm 0,4$ & $2,6 \pm 0,5$ & $2,9 \pm 0,4$ & $1,0 \pm 0,0$ \\
\hline 5 & $2,8 \pm 0,6$ & $1,0 \pm 0,0$ & $2,1 \pm 0,6$ & $2,75 \pm 0,5$ & $1,0 \pm 0,0$ \\
\hline 8 & $1,9 \pm 0.6$ & $1,0 \pm 0,0$ & $1,5 \pm 0,5$ & $2,3 \pm 0,5$ & $1,0 \pm 0,0$ \\
\hline 15 & $1,0 \pm 0,0$ & $1,0 \pm 0,0$ & $1,0 \pm 0,0$ & $1,3 \pm 0,5$ & $1,8 \pm 0,5$ \\
\hline 20 & $1,0 \pm 0.0$ & $1,0 \pm 0,0$ & $1,0 \pm 0,0$ & $1,0 \pm 0,0$ & $2,0 \pm 0,0$ \\
\hline 30 & $1,0 \pm 0,0$ & $1,0 \pm 0,0$ & $1,0 \pm 0,0$ & $1,0 \pm 0,0$ & $2,0 \pm 0,0$ \\
\hline
\end{tabular}




\section{Экспериментальные исследования}

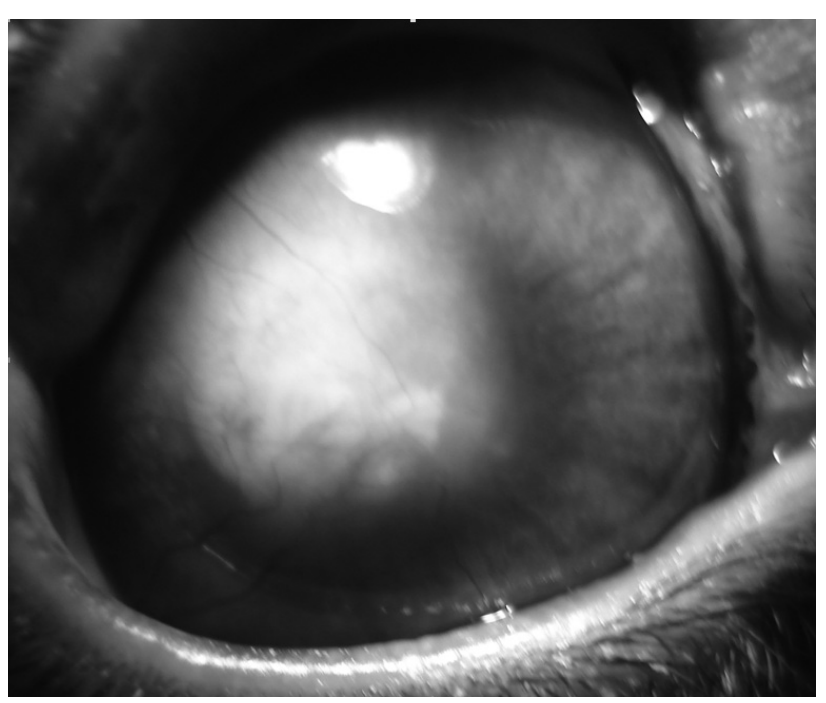

Рис. 2. Фотография глаза кролика контрольной группы с кератитом средней степени, исход - локальное стромальное помутнение с неоваскуляризацией.

При тяжелом течении (7 глаз) через сутки после вмешательства наблюдался блефароспазм, гиперемия конъюнктивы, отделяемое из конъюнктивальной полости, эрозия роговицы, выраженный отек эпителия и наружных слоев стромы роговицы и стромальные инфильтраты роговицы. Признаки воспаления были наиболее выраженными на третьи сутки после инфицирования, а также наблюдался бурный рост Candida albicans по данным бактериологического исследования. Начиная с 15-х суток отмечалось угасание признаков воспаления: уменьшение гиперемии конъюнктивы, интенсивности отека эпителия роговицы, отсутствие прокрашивания флюоресцеином, что свидетельствовало о полной эпителизации эрозии. На 20-е сутки отмечалось постепенное рассасывание инфильтратов (табл. 2). Длительность кератита тяжелой степени $(7$ глаз $)-(21,1 \pm 1,7)$ дней, исход - выраженное стромальное помутнение с активной неоваскуляризацией (рис. 3). Роста патогенной флоры нет.

Таблица 2

Оценка (в баллах) течения моделированного грибкового кератита тяжелой степени у кроликов контрольной группы (в баллах)

\begin{tabular}{|c|c|c|c|c|c|}
\hline Сутки & $\begin{array}{c}\text { Гипе- } \\
\text { ремия } \\
\text { конъюн- } \\
\text { ктивы }\end{array}$ & $\begin{array}{c}\text { Эрозия } \\
\text { роговицы }\end{array}$ & $\begin{array}{c}\text { Отек ро-- } \\
\text { говищы }\end{array}$ & $\begin{array}{c}\text { Инфиль- } \\
\text { трация } \\
\text { роговицы }\end{array}$ & $\begin{array}{c}\text { Помут- } \\
\text { нение } \\
\text { роговицы }\end{array}$ \\
\hline $\begin{array}{c}\text { До зара- } \\
\text { жения }\end{array}$ & $1,0 \pm 0,0$ & $1,0 \pm 0,0$ & $1,0 \pm 0,0$ & $1,0 \pm 0,0$ & $1,0 \pm 0.0$ \\
\hline 1 & $3,6 \pm 0,5$ & $2,0 \pm 0,0$ & $2,7 \pm 0,5$ & $2,3 \pm 0,5$ & $1,0 \pm 0,0$ \\
\hline 3 & $4,0 \pm 0,0$ & $2,0 \pm 0,0$ & $3,0 \pm 0,0$ & $3,0 \pm 0,0$ & $1,0 \pm 0,0$ \\
\hline 5 & $4,0 \pm 0,0$ & $1,7 \pm 0,5$ & $3,0 \pm 0,0$ & $3,0 \pm 0,0$ & $1,0 \pm 0,0$ \\
\hline 8 & $3,3 \pm 0.5$ & $1,0 \pm 0,0$ & $2,4 \pm 0,5$ & $2,9 \pm 0,4$ & $1,0 \pm 0,0$ \\
\hline 15 & $2,4 \pm 0,7$ & $1,0 \pm 0,0$ & $1,7 \pm 0,8$ & $2,7 \pm 0,5$ & $1,0 \pm 0,0$ \\
\hline 20 & $1,3 \pm 0.7$ & $1,0 \pm 0,0$ & $1,1 \pm 0,4$ & $2,0 \pm 0,0$ & $1,0 \pm 0,0$ \\
\hline 30 & $1,0 \pm 0,0$ & $1,0 \pm 0,0$ & $1,0 \pm 0,0$ & $1,0 \pm 0,0$ & $2,0 \pm 0,0$ \\
\hline
\end{tabular}

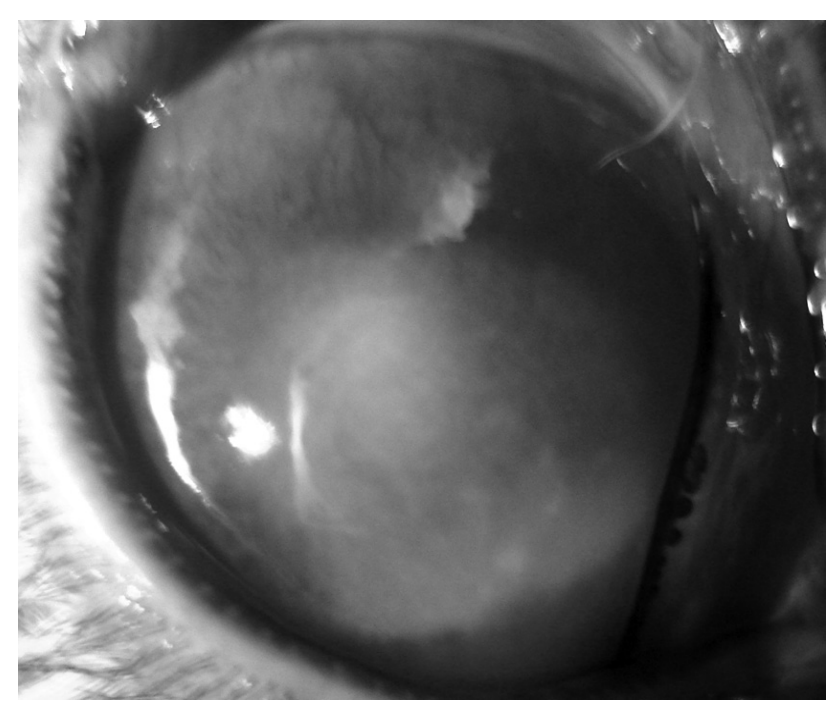

Рис. 3. Фотография глаза кролика контрольной группы с кератитом тяжелой степени, исход - выраженное стромальное помутнение с активной неоваскуляризацией.

В основной группе с кератитом средней степени (6 глаз) через сутки после вмешательства у всех кроликов появились блефароспазм, гиперемия конъюнктивы, отделяемое из конъюнктивальной полости, эрозия роговицы, выраженный отек эпителия и наружных слоев стромы роговицы и стромальные инфильтраты роговицы. На третьи сутки по данным бактериологического исследования - бурный pocт Candida albicans, воспалительный процесс был выражен максимально. На 5-е сутки отмечалась полная эпителизация нанесенной эрозии, что подтверждалось флюоресцеиновой пробой, уменьшение интенсивности отека эпителия роговицы. Наблюдалось постепенное рассасывание инфильтратов на 8-е сутки (табл. 3). Длительность кератита средней степени (6 глаз) составила $(7,1 \pm 0,75)$ дней, исход - поверхностные точечные помутнения, прозрачность роговицы восстановилась на 5 глазах (83\%) через 16 дней (рис. 4). Роста патогенной флоры нет.

Таблица 3

Оценка (в баллах) течения моделированного грибкового кератита средней степени тяжести у кроликов основной группы (в баллах)

\begin{tabular}{|c|c|c|c|c|c|}
\hline Сутки & $\begin{array}{c}\text { Гипе- } \\
\text { ремия } \\
\text { конъюн- } \\
\text { ктивы }\end{array}$ & $\begin{array}{c}\text { Эрозия } \\
\text { роговицы }\end{array}$ & $\begin{array}{c}\text { Отек ро- } \\
\text { говицы }\end{array}$ & $\begin{array}{c}\text { Инфиль- } \\
\text { трация } \\
\text { роговицы }\end{array}$ & $\begin{array}{c}\text { Помут- } \\
\text { нение } \\
\text { роговицы }\end{array}$ \\
\hline $\begin{array}{c}\text { Дозара- } \\
\text { жения }\end{array}$ & $1,0 \pm 0,0$ & $1,0 \pm 0,0$ & $1,0 \pm 0,0$ & $1,0 \pm 0,0$ & $1,0 \pm 0.0$ \\
\hline 1 & $3,0 \pm 0,6$ & $2,0 \pm 0,0$ & $2,0 \pm 0,0$ & $2,2 \pm 0,4$ & $1,0 \pm 0.0$ \\
\hline 3 & $3,3 \pm 0,8$ & $1,6 \pm 0,5$ & $2,3 \pm 0,5$ & $2,5 \pm 0,5$ & $1,0 \pm 0,0$ \\
\hline 5 & $2,2 \pm 0,4$ & $1,0 \pm 0,0$ & $1,5 \pm 0,5$ & $2,0 \pm 0,6$ & $1,2 \pm 0,4$ \\
\hline 8 & $1,0 \pm 0,0$ & $1,0 \pm 0,0$ & $1,0 \pm 0,0$ & $1,3 \pm 0,5$ & $1,7 \pm 0,5$ \\
\hline 15 & $1,0 \pm 0,0$ & $1,0 \pm 0,0$ & $1,0 \pm 0,0$ & $1,0 \pm 0,0$ & $1,8 \pm 0,4$ \\
\hline 20 & $1,0 \pm 0,0$ & $1,0 \pm 0,0$ & $1,0 \pm 0,0$ & $1,0 \pm 0,0$ & $1,2 \pm 0,4$ \\
\hline 30 & $1,0 \pm 0,0$ & $1,0 \pm 0,0$ & $1,0 \pm 0,0$ & $1,0 \pm 0,0$ & $1,2 \pm 0,4$ \\
\hline
\end{tabular}




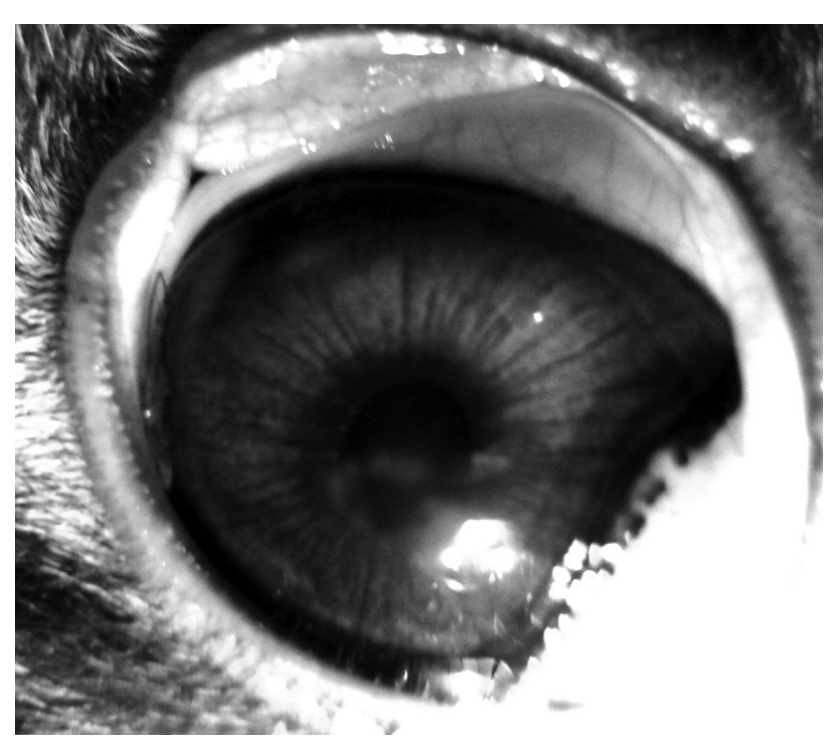

Рис. 4. Фотография глаза кролика основной группы с кератитом средней степени, исход - поверхностные точечные помутнения.

При тяжелом течении кератита (9 глаз) через сутки после вмешательства наблюдались блефароспазм, гиперемия конъюнктивы, отделяемое из конъюнктивальной полости, эрозия роговицы, выраженный отек эпителия и наружных слоев стромы роговицы, а также стромальные инфильтраты роговицы. Признаки воспаления наиболее выраженными были на третьи сутки после заражения, по данным бактериологического исследования бурный рост Candida albicans. Начиная с пятых суток отмечалось угасание признаков воспаления: уменьшение гиперемии конъюнктивы, интенсивности отека эпителия роговицы, при пробе с флюоресцеином - определялась полная эпителизация эрозии. Через 15 суток отмечалось постепенное рассасывание инфильтратов (табл. 4). Длительность кератита тяжелой степени - $(14,25 \pm 1,0)$ дней, исход - легкое локальное стромальное помутнение с запустевшими сосудами (рис. 5). Роста патогенной флоры нет.

Таблица 4

Оценка (в баллах) течения моделированного грибкового кератита тяжелой степени у кроликов основной группы (в баллах)

\begin{tabular}{|c|c|c|c|c|c|}
\hline Сутки & $\begin{array}{c}\text { Гипе- } \\
\text { ремия } \\
\text { конъюн- } \\
\text { ктивы }\end{array}$ & $\begin{array}{c}\text { Эрозия } \\
\text { роговицы }\end{array}$ & $\begin{array}{c}\text { Отек ро- } \\
\text { говицы }\end{array}$ & $\begin{array}{c}\text { Инфиль- } \\
\text { трация } \\
\text { роговицы }\end{array}$ & $\begin{array}{c}\text { Помут- } \\
\text { нение } \\
\text { роговицы }\end{array}$ \\
\hline $\begin{array}{c}\text { Дозара- } \\
\text { жения }\end{array}$ & $\mathbf{1 , 0 \pm 0 , 0}$ & $\mathbf{1 , 0 \pm 0 , 0}$ & $\mathbf{1 , 0} \pm \mathbf{0 , 0}$ & $\mathbf{1 , 0 \pm 0 , 0}$ & $\mathbf{1 , 0 \pm 0 . 0}$ \\
\hline 1 & $3,1 \pm 0,3$ & $2,0 \pm 0,0$ & $2,7 \pm 0,5$ & $2,3 \pm 0,5$ & $1,0 \pm 0.0$ \\
\hline 3 & $3,7 \pm 0,4$ & $2,0 \pm 0,0$ & $3,0 \pm 0,0$ & $2,9 \pm 0,3$ & $1,0 \pm 0,0$ \\
\hline 5 & $2,6 \pm 0,5$ & $1,0 \pm 0,0$ & $2,1 \pm 0,3$ & $2,3 \pm 0,5$ & $1,0 \pm 0,0$ \\
\hline 8 & $1,8 \pm 0,3$ & $1,0 \pm 0,0$ & $1,7 \pm 0,5$ & $2,1 \pm 0,3$ & $1,0 \pm 0,0$ \\
\hline 15 & $1,0 \pm 0,0$ & $1,0 \pm 0,0$ & $1,0 \pm 0,0$ & $1,3 \pm 0,5$ & $1,7 \pm 0,5$ \\
\hline 20 & $1,0 \pm 0,0$ & $1,0 \pm 0,0$ & $1,0 \pm 0,0$ & $1,0 \pm 0,0$ & $2,0 \pm 0,0$ \\
\hline 30 & $1,0 \pm 0,0$ & $1,0 \pm 0,0$ & $1,0 \pm 0,0$ & $1,0 \pm 0,0$ & $2,0 \pm 0,0$ \\
\hline
\end{tabular}

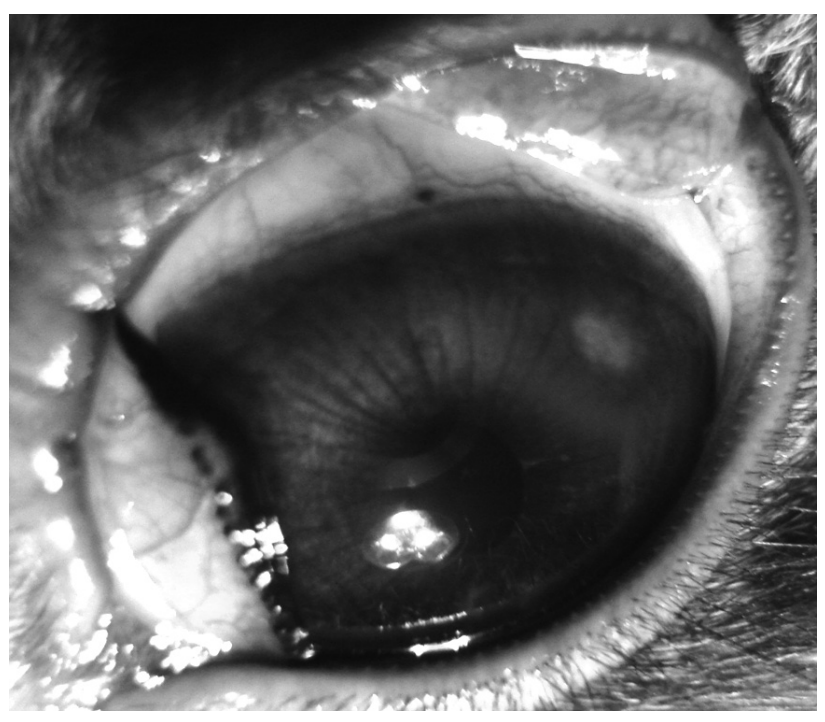

Рис. 5. Фотография глаза кролика основной группы с кератитом тяжелой степени, исход - легкое локальное стромальное помутнение с запустевшими сосудами.

Таким образом, длительность течения грибкового кератита средней степени у кроликов, пролеченных ФДТ с метиленовым синим (основная группа), вдвое меньше, чем у животных контрольной группы $(\mathrm{p}<0,05)$. При проведении ФДТ с МС у кроликов основной группы с тяжелым кератитом мы добились выздоровления на 7 суток раньше, чем у кроликов контрольной группы (на 14,25 $\pm 1,0$ день основная группа, на 21,1士1,7 день - контрольная, $\mathrm{p}<0,05)$.

Заключение. В результате проведенного исследования установлено, что модифицированная модель грибкового кератита позволяет получить грибковый кератит средней и тяжелой степени тяжести. Лечение грибковых кератитов посредством ФТД с метиленовым синим в качестве фотосенсибилизатора в эксперименте, позволяет сократить сроки лечения и добиться заживления роговицы с более высоким оптическим результатом, чем применение стандартной противовоспалительной терапии.

\section{СПИСОК ЛИТЕРАТУРЫ}

1. Behrens-Baumann W. Mycosis of the eye and adnexa / W. Behrens-Baumann // Developments in ophthalmology. KARGER. - Vol. 32. - P. 201.

2. Chern KC. Corneal anesthetic abuse and Candida keratitis / KC. Chern, DM. Meisler, KR. Wilhelmus et all // Ophthalmology. - 1996. - Vol. 103. - P. 37-40.

3. Ishibashi Y. Keratomycosis in Japan reported from 1976 to 1980 [in Japanese] / Y. Ishibashi // Nippon Ganka Gakkai Zasshi. - 1982. - Vol.86. - P. 651-656.

4. Poria VC. Study of mycotic keratitis / VC. Poria, VR. Bharad, DS. Dongre, MV. Kulkarni // Indian J Ophthalmol. 1985. - Vol.33. - P.229-231.

5. Schreiber W. Fluconazole and corticosteroid treatment in keratomycosis IOVS // W. Schreiber, A. Olbrisch, C. K. Vorwerk et all - June 2003. - vol. 44. - № 6. P. 2634-2643. 
6. Sundaram BM. Studies on mycotic keratitis / BM. Sundaram, S. Badrindath, S. Subramanian // Mycoses. 1989. - Vol. 32. - P.568-572.

7. Wilson LA. Association of fungi with extended-wear soft contact lenses / LA. Wilson, DG. Ahearn // Am J Ophthalmol. - 1986. - Vol.101. - P.434-436.
8. Гайдамака Т. Б. Новый способ моделирования вирусного кератита / Т. Б. Гайдамака // Офтальмологический журнал. - 1999. - № 6. - С. 429-431.

Поступила 07.02.2011.

УДК 617.731-007.23:615.91-003.93-092.4

\title{
ВЛИЯНИЕ ПРЕПАРАТА ПОЛИОКСИДОНИЙ НА ПРОЦЕССЫ РЕПАРАЦИИ ЗРИТЕЛЬНОГО НЕРВА ПРИ ЭКСПЕРИМЕНТАЛЬНОЙ ХРОНИЧЕСКОЙ АЛКОГОЛЬНОЙ ИНТОКСИКАЦИИ
}

\author{
О. В. Недзвецкая, Д. М. Н., профессор; Д. А. Петрушенко, врач \\ Харьковская медицинская академия последипломного образования, г. Харьков; \\ КУ Сумская областная клиническая больница, г. Сумы
}

\begin{abstract}
Проведено гістоморфологічне дослідження процесів репарації після лікування препаратом поліоксидоній у інтрабульбарному, ретробульбарному, интраканалікулярному та інтракраніальному відділах зорового нерва при його ураженні внаслідок хронічної алкогольної інтоксикації в експерименті. Дослідженням, проведеним на 24 кроликах самиях породи шиншила, встановлено, що після лікування в усіх досліджених відділах зорового нерву: 1) припиняються процеси альтерації, на що вказує зникнення морфологічних ознак розпаду мієлінових оболонок нервових волокон; 2) різко активізуються компенсаторно-пристосувальні та регенераторні процеси, що морфологічно виражсається гіперплазією судинної сітки та нервових волокон зорового нерва. Зважаючи на позитивний вплив лікування препаратом поліоксидоній на процеси регенерації в зоровому нерві після припинення вживання алкоголю, а також відсутність морфологічних ознак стимуляції аутоімунних процесів, синтетичний імуномодулятор поліоксидоній можна вважати перспективним для лікування токсичної оптичної нейропатії алкогольного тенезу у людей.
\end{abstract}

Ключевые слова: хроническая алкогольная интоксикация, зрительный нерв, токсическая оптическая нейропатия, демиелинизация, регенерация, полиоксидоний.

Ключові слова: хронічна алкогольна інтоксикація, зоровий нерв, токсична оптична нейропатія, демієлінізація, регенерація, поліоксидоній

Введение. Известно, что при хронической алкогольной интоксикации (ХАИ) развивается атрофия нервных волокон зрительного нерва (3Н) с частичным распадом миелиновых оболочек. Наиболее выраженные альтеративные изменения определяются в ретробульбарной и внутриканальцевой части $3 \mathrm{H}$. Характерным для ХАИ являются поражение папилломакулярного пучка, а также склероз артерий и артериол, периваскулярное разрастание соединительной ткани, пролиферация и десквамация эндотелия, разрастание глии. Исследования показывают, что вышеуказанные изменения обратимы лишь частично $[1,2,5,8]$.

В последние годы все большее признание и распространение приобретает теория иммунологической регуляции процессов регенерации. Первоначально влияние иммунной системы на репаративные процессы связывали с повреждающим воздействием гуморальных антител на стареющие и измененные клетки. На сегодня доказано, что иммунная система выполняет не только цензорную функцию, но и морфогенетическую [6]. С этой точки зрения представляют интерес возможности целенаправленного воздействия на иммунную систему для стимуляции процессов регенерации. Это направление в лечении глазных заболеваний является мало изученным. М. В. Черешнева и соавторы показали, что применение синтетического иммуномодулятора полиоксидония при воспалительных заболеваниях роговицы и хориоидеи оптимизирует регенераторный процесс, способствует формированию более упорядоченной бессосудистой рубцовой ткани при незначительной выраженности реактивных изменений [7]. В то же время, влияние полиоксидония на процессы регенерации в зрительном нерве ранее не изучалось.

Цель исследования: изучить влияние препарата полиоксидоний на процессы репарации в зрительном нерве при его токсическом поражении вслед-

(C) О. В. Недзвецкая, Д. А. Петрушенко, 2011 